\title{
Resenha
}

Educação inclusiva: para todos ou para cada um?

Alguns paradoxos (in)convenientes Silva, K. C. B. São Paulo, SP: Escuta; Fapesp, 2016, 320 p.

\section{SOBRE TRANCAS E NÓS: O INSOLÚVEL DA EDUCAÇÃO INCLUSIVA}

\author{
Karina de Queiroz Bueno \\ DOl: http//dx.doi.ors/10.11606/issn. 1981-1624.v21i3p772-777.
}

Kelly Cristina Brandão da Silva em Educação inclusiva: para todos ou para cada um? Alguns paradoxos (in)convenientes nos oferece uma imersão no tema da educação inclusiva ao propor uma análise do significante "especial" que paradoxalmente se enoda na inclusão. Segundo a autora "se a educação inclusiva tem como prerrogativa a inclusão de todos os alunos preferivelmente no ensino regular, por que o termo especial tem tanto destaque?" (Silva, 2016, p. 15). É a partir desse questionamento que Silva constrói sua tese, elencando alguns elementos que parecem emaranhados na trama da inclusão, com nós bem sintetizados, alguns já frouxos e outros ligados quase que por um fio.

Abre-se assim, uma discussão contemporânea do fenômeno da inclusão, em que o furor includenti impulsiona uma amarração total, sem sobrar ninguém do lado de fora. Entretanto, mostrando o outro lado do mesmo pano (Voltolini, 2011), ao tentar benevolentemente incluir a todos, esquecemo-nos do que seria sua contrapartida, isto é, a exclusão. Silva faz uma recuperação da origem etiológica latina dos termos inclusão "fechar por dentro a chave, incluir" e exclusão

- Psicanalista. Mestranda na Faculdade de Educação da Universidade de São Paulo. Membro do Laboratório de Estudos e Pesquisas Psicanalíticas e Educacionais sobre a Infância, São Paulo, SP, Brasil. 
"deixar trancado para fora, excluir", possibilitando a percepção de que os dois mecanismos trazem a ação de isolar, seja para dentro ou para fora. Aqui encontramos o problema central abordado pelo livro: se a inclusão tem o ideal de agrupar, como esse inconveniente avesso do isolar consiste em aparecer?

A escolha por articular com Foucault os termos de inclusão e exclusão, esclarece que enquanto excluíam-se os leprosos, por exemplo, em uma tentativa de manter fora da cidade os doentes e deixar a pólis "limpa", aqueles que contraiam a peste acabavam enclausurados dentro de suas casas, vigiados e controlados pelo Estado. "Enquanto a exclusão é o afastamento, o desconhecimento, a inclusão parece ser o modelo do conhecimento, do exame, de uma observação próxima e meticulosa" (Silva, 2016, p. 36-37).

As crianças "especiais" que antes eram isoladas em suas casas e excluídas das escolas regulares, a partir da Declaração de Salamanca (1994), se constituem legalmente como "crianças escolares" (Kupfer, 2001). Ao entrar nas instituições educativas o inconveniente de controlar e vigiar esses novos alunos urge e os especialistas são chamados para realizar/ auxiliar/orientar na inclusão desses que poderiam ser considerados os "pestilentos contemporâneos", diz Silva (2016, p. 40).

Com a finalidade de investigar certo excesso de "especialização" na regulação na trama discursiva da educação inclusiva no Brasil, Silva optou por analisar os textos da revista Nova Escola publicados entre 1994 e 2012 a partir do recorte educação especial, educação inclusiva e especialista. Em uma aliança com o Governo Federal, a revista passou a ser o principal difusor de propostas oficiais e novas políticas públicas para professores. A trama da educação - geral e inclusiva - aparece então cerceada pelo saber do especialista - médico e jurista - além de um campo para a aplicação e administração desses discursos de fora da escola. O "como fazer" aparece exigindo do especialista uma resposta rápida e eficiente, tamponando qualquer interrogação ou buraco do cotidiano educacional.

Silva também articula com Hannah Arendt, Walter Benjamin e Jacques Lacan algumas vicissitudes da contemporaneidade. A começar com Arendt, uma filósofa que não era especialista em educação, mas nos oferece importantes reflexões sobre a crise na atualidade - que seria a perda de uma experiência narrativa entre os velhos e os novos, uma extinção do fio que nos liga aos domínios do passado. Nesse sentido, a educação também estaria em crise já que "se trata da transmissão de uma herança simbólica, compartilhada” (Silva, 2016, p. 59). Com a 
C entrada do saber especializado na es-

는 cola, fica quase extinta a transmissão de uma experiência - para no lugar ser repassado um saber anônimo e replicável do tecnocientificismo - e se esgota "o enigma concernente à assi(U) metria entre os pequenos e os velhos, U na tentativa de anular toda e qualquer $\boldsymbol{\alpha}$ estranheza que porventura ousasse desvelar no encontro - sempre impre- visível - entre alunos e professores" (Silva, 2016, p. 64).

ப- Ao abordar a questão do fim da O experiência, Silva recorre às reflexões Ude Benjamin, para quem a experiência de narrar e transmitir histórias estaria sumindo na modernidade. Nesse sentido, a obsolescência da tradição para Kehl (2009) citada por Silva (2016, p. 75) "produz um sujeito permaU nentemente disponível, pronto a se $\boldsymbol{\alpha}$ desfazer de suas referências em troca de novidades em oferta". Ora, a que 工 nó chegamos! O saber especializado oferecendo "como fazer" específico Uaos professores vazios de experiência S narrativa que, por sua vez, marcarão em argila ou vidro ${ }^{2}$ ? - seus alunos que um dia se tornarão adultos e terão sua hora e vez de narrar - ou não - suas experiências.

Como uma possível tentativa de furo nessa cíclica trama encontramos ainda, em Benjamin, a "crença na necessidade de resistir" a toda previsibilidade, sistematização, classificação, Ireduzindo a complexidade humana Zem algo simplório (Silva, 2016, p. 84). 는 Considerando Benjamin, Silva aponta U para a necessidade de acreditar na $\alpha$ permanente "insuficiência do conhecimento", sendo esta estrutural e não contingencial, como aparece nos saberes especializados tecnocientíficos.

Para aprofundar a discussão concernente aos especialistas invocados e convocados à trama educacional, a autora trabalha com a teorização lacaniana dos discursos. Enquanto um "liame social", os discursos são formas de laço fundamentadas nas impossibilidades imposta pela linguagem a qual "não dá conta de toda experiência humana, restando sempre algo que não cessa de não se inscrever"' (Silva, 2016, p. 86). Nesse sentido, como almejamos invocar e convocar algum especialista ou inclusão que abarque tudo?

Mais ainda, alinhada à crença na necessidade de resistir benjaminiana e na insuficiência do conhecimento, a noção dos discursos lacanianos, por apontar estruturalmente para um inalcançável (Voltolini, 2011, p. 25), possibilita mudanças de posição do sujeito, já que um discurso só é lido em função do outro. Assim, segundo a autora, podemos perceber uma mudança de posição discursiva "especialmente" da educação inclusiva, de uma posição de mestria para uma aliança entre os discursos universitário e capitalista (Silva, 2016, p. 99). Resta-nos analisar os sentidos e efeitos dessa "formação de compromisso" (Silva, 2016, p. 105) para a trama da educação inclusiva.

Para tanto, Silva traz a sistematização dos textos analisados na Nova Escola a partir de quatro eixos: a transversalidade da Educação Especial; 
o professor como especialista; protocolos da educação inclusiva; e parceria entre escola e família que se entrecruzam. A partir da análise dos documentos jurídicos oficiais podemos perceber os significantes "especial”, "especializado" e "especialista", compondo-os literalmente. A educação "especial" tanto na LDB antiga (1961) como na nova (1996) aparecem as noções de tratamento especializado, atendimento educacional, apoio de diversos atores. "Tratamento", "atendimento", "apoio", qual o sentido dessa inclusão de termos relacionados ao campo da saúde à educação?

De tal análise podemos perceber que historicamente as instituições fundadas para o atendimento do especial já eram pautadas nas discriminações e catalogações das diferenças (Silva, 2016, p. 124). Além disso, há uma naturalização na classificação das deficiências, que localiza a de-ficiência - não eficiente - de modo orgânico, a-histórico. Vemos então, uma supressão do sujeito perante a objetividade científica. Atrelado a isso está o discurso psicologizante em que podemos observar a aliança entre a Psicologia e a Medicina, que, de acordo com Patto (1984), citada por Silva (2016, p. 132), "instaura o miolo teórico-conceitual da psicologia uma analogia da ideologia adaptacionista como concepção que norteia a ação do psicólogo".

O psicólogo entra na trama educativa com a tarefa de avaliar e selecionar os mais aptos a estar na sala de aula e identificar os fracassos escolares. Daí a necessidade e peso dos laudos - não somente psicológicos, mas médicos e jurídicos - atravessando o campo pedagógico como formas de justificar e embasar as ações do cotidiano educacional. Além das avaliações e laudos, há também os protocolos e normas reguladoras presentes na educação inclusiva - ou educação de maneira geral. "Protocolo" nas áreas da Saúde configuram como "uma série de diretrizes baseadas em evidências, as quais visam à prevenção do erro" (Silva, 2016, p. 202). Ou seja, as condutas protocolares na cena educativa denunciam o desejo de ter um saber catalogado a priori sobre o que vai acontecer ou chances de minimização dos erros e frustações diante das impossibilidades estruturais do "ato educativo” (Lajonquière, 1999).

Por fim, e não menos importante, Silva traz a questão dita como "imprescindível" de uma parceria entre a escola e a família para pensarmos mais sentidos sobre a aliança de compromisso feita entre a educação e o discurso especialista na trama da Educação Inclusiva. Por que a necessidade de uma complementaridade dessas esferas? Para Silva (2016, p. 222), a complementaridade traz um ideal de continuidade, ou seja, parece que nem a escola nem a família estão sustentando a posição de mestria necessária para o ato educativo diante dos novos. Quando se espera que a escola seja uma continuidade da família, 
tanto o âmbito familiar quanto o âmbito escolar se descaracterizam (Silva, 2016, p. 232). Surge a necessidade de completude novamente, alinhada ao ideal de quanto mais se conhece, mais fácil a dominação do saber científico especializado.

Silva discute a hipnotizante noção de educação inclusiva "para todos e para cada um". A partir da teoria pulsional freudiana que atribui à pulsão um caráter irredutível e da articulação com a parábola de Schopenhauer do porco-espinho, podemos pensar que em se tratando de relações humanas sempre estaremos entre o frio para não nos espetarmos e o espinho para nos aquecermos. Há sempre uma justa medida, ou o que Freud denominou de "ponto ótimo" (Freud, 1933/1996, p. 147) insolúvel que a educação precisa buscar.

Nas palavras de Voltolini (2011, p. 68), "atingir o bom termo entre unificar sem aniquilar as diferenças e permitir as diferenças sem que isso ameace a conservação de um mínimo solo comum?". Trancar por dentro todos "globalmente" ou trancar por dentro cada um "sob medida"? Silva aponta, em Educação inclusiva, para o dilema insolúvel da trama educacional a partir da característica artesanal de como, enfim, se afrouxar os nós das especialidades, para que restem brechas no fio educativo a ser transmitido.

\section{REFERÊNCIAS}

Freud, S. (1996). Novas Conferências Introdutórias sobre a Psicanálise - Conferência XXXIV: "Explicaçôes, Aplicaçóes e Orientaçôes". In S. Freud, Ediçôes standard brasileira das obras psicológicas completas de Sigmund Freud (J. Salomão, trad., Vol. 22, pp. 135-154). Rio de Janeiro, RJ: Imago. (Trabalho original publicado em 1933)

Kupfer, M. C. M. (2001). Duas notas sobre a inclusão escolar. Escritos da criança, 1,71-82.

Lajonquière, L. (1999). Infância e ilusão (psico)pedagógica: escritos de Psicanálise e Educação. Petrópolis, RJ: Vozes.

Silva, K. C. B. (2016). Educação inclusiva: para todos ou para cada um? Alguns paradoxos (in) convenientes. São Paulo, SP: Escuta; Fapesp.

Voltolini, R. (2011). Educação e psicanálise. Rio de Janeiro, RJ: Jorge Zahar

\section{NOTAS}

1. Segunda maior tiragem de revistas do país, perdendo apenas para a revista Veja. A revista está em circulação desde março de 1986 e é subsidiada pelo Governo Federal - o que explica seu baixo custo e grande inserção nas instituiçôes escolares públicas brasileiras (Silva, 2016, pp. 42-43).

776 Estilos clin., São Paulo, v. 21, n. 3, set./dez. 2016, 772-777. 
2. Silva nos traz duas metáforas abordadas por Benjamin sobre a experiência de deixar marcas/ rastros do narrador. O ritmo do trabalho artesanal possibilita a arte de contar, de fazer movimentos precisos que respeitam a matéria a ser transformada. São ritmos lentos e orgânicos que deixam marcas, como o oleiro na argila. Já as marcas do vidro são consideradas sujeiras, que precisam ser apagadas.

karinaqueirozbueno@gmail.com Rua Itapicuru, 930, sala 4 05006-000 - São Paulo - SP - Brasil. 